\title{
Interactive comment on "Climate reconstructions based on GDGT and pollen surface datasets from Mongolia and Siberia: calibrations and applicability to extremely cold-dry environments over the Late Holocene" by Lucas Dugerdil et al.
}

Anonymous Referee \#3

Received and published: 25 February 2021

This paper presented valuable data sets of pollen assemblage and bacterial branched GDGTs from Mongolia and Siberia that are both extremely dry and cold regions. Regional or local calibrations for temperature and precipitation reconstruction were developed based on the relationship of pollen assemblages and the distribution of brGDGTs with climatic parameters. The authors then used two sediment profiles published in other studies to validate their proposed calibrations and posited that the calibrations were applicable to the cold and dry regions, as stated in the title. This study is valuable in terms of the scarcity of pollen assemblage and bacterial brGDGT data from Mongo- 
lian and Siberian soils. This paper is generally well written. But the phrases or wording in this paper need to be improved, as can be seen below. I also have some concerns that need to be clearly addressed. First, the authors have mentioned 7-methyl brGDGTs that were not widely present in soils. So I am not so convinced that the compounds they identify in these soils are 7-methyl brGDGTs since they do not provide any useful information to support this. This, however, needs to be accurate. Second, the paper discussed two types of environmental indicators: pollen and brGDGTs, thus providing abundant information. However, in other words, the paper is rather complex and unfocused. I would write pollen and brGDGTs in two separate papers. The combination of them into one paper results in insufficient discussions. For example, I do not see many discussions about the pollen and mechanisms behind the environmental control on brGDGTs and pollen in such extremely cold and dry regions. The response of pollen and brGDGTs to precipitation and temperature was dependent on biochemical mechanisms. The model or calibrations developed by statistical methods should be consistent with these mechanisms. Third, the authors developed calibrations based on brGDGTs in Mongolian soils; however, no paleo sequences or loess-like sediments can be used in this region to assess the applicability of these calibrations. So I questioned the value of these calibrations. Fourthly, different types of sediments were used in this paper, e.g., muds, soils, and moss. I learn from previous studies that brGDGTs might have different sources in different sediments. So we can see calibrations specific for each environment have been proposed over the last decade. I am very confused about the use of all these sediments in the development of a calibration. Other concerns are listed below for your consideration.

Line 34 '?' Question mark. References needed here. Line 46 Change 'leads' to 'lead' Line 57 Redundant. Pls delete 'and agree well'. Line 63 'Damsté et al., 2000' should be 'Sinninghe Damsté et al., 2000' Line 69 'Salvador-Castel et al., 2019 in press' Pls list this reference in the reference list. Line 71-72 'bacterial community structure (Xie et al., 2015), the bacterial group response(Knappy et al., 2011) and the GDGT occurrences in different bacterial communities (Liu et al., 2012b) to. All these references

Printer-friendly version

Discussion paper

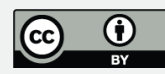


are related to archaea that completely differ from bacteria. They are archaeal community and archaeal group, not bacterial community. Line 75 MBT and CBT need to be defined since they appear for the first time. Line 76-77, 78 'reacts' better use 'respond'. Add brGDGTs after '5-methyl', add '-' after '5,6' Line 78 Add brGDGTs after '6-methyl'. Line 84 'Ri/b' should be defined upon its first occurrence in the text. Line 130-135 Mud from ponds generally contains GDGT distribution that differs markedly from neighboring soils. The calibration for pond-like sediments is also different from that of soils. I cannot agree with the incorporation of mud sediments in developing calibrations for soil environments. Line 171 'precipitations' changed to 'precipitation'. Line $224 \mathrm{APCl}$ needs to be explained for the wide readership of the journal. What is 'LGLTPE-ENS de Lyon'? Line 226-230 I found from the Result part (figure 4) that the authors have identified a series of 7-methyl brGDGTs, which were not widely seen in soils and lakes. Please provide the details as to how these compounds were identified and assigned in the text so that reviewers can assess whether they are identified in a right way. Line 261 and Figure 3 captions What are 'AP' and 'NAP'? Please define this term prior to use. Line 279-280 Please show the determination coefficients and $p$ values for the correlations Table 1 It is a little bit confusing to see so many abbreviations in the table. Please provide notes below the table. Line 312 '74.6\%' I think this may be the average abundance of each compound for all the soil samples. Please specify. Line 316 diverge from surface soil samples? Please make it clear. Line 316-317 The same iGDGT distribution between soil and lake sediments does not necessarily indicates a significant contribution of GDGTs to the lake. GDGT-0 dominates over crenarchaeol in these soils, probably reflecting a high alkalinity of the soils or a dominance of methanogenic Euryarchaeota due to the anoxic environments in the moss. In contrast, the dominance of GDGT-0 over crenarchaeol in lake sediments might indicate that abundant methanogenic Euryarchaeota inhabit the anoxic lake sediments yet few Thaumarchaeota live in the lake. Line 317 'soil-produced' changed to 'produced in soils' Line 318 '[crenarcheol]' What does the bracket indicate? Please specify in the text. Line 319 What does 'reaction' mean? Line 327 Reduce '22.77\%' to one significant

\section{CPD}

Interactive comment
Printer-friendly version

Discussion paper 
figure. Line 341 'methyled and cyclized' changed to 'methylated and cyclized' Line 349 Add '-' after ' 5 and 6'. Line 376 Add 'brGDGTs' after '6-methyl'. Line 396 O2 Line 417 'react' Not properly used word. Line 442 'affects' changed to 'affect'. Line 502 extreme Figure 10 captions 'foe each cores' 'for each core'. Line 567 drier

CPD

Interactive comment on Clim. Past Discuss., https://doi.org/10.5194/cp-2020-154, 2020.

Interactive

comment 